\title{
(6) OPEN ACCESS \\ Giant cell arteritis presenting with bilateral orbital inflammatory disease and enhancing superficial temporal arteries
}

\author{
Jamie R Mitchell, ${ }^{1}$ Iris Krashin-Bichler, ${ }^{2}$ Marc Rosenblum, ${ }^{3}$ \\ Eli L Diamond, ${ }^{4}$ Marc J Dinkin ${ }^{1}$
}

${ }^{1}$ Department of Ophthalmology, Weill Cornell Medical Center, New York, New York, USA ${ }^{2}$ Department of Ophthalmology, Tel Aviv Medical Center, Tel Aviv, Israel

${ }^{3}$ Department of Pathology, Memorial Sloan-Kettering Cancer Center, New York, New York, USA

${ }^{4}$ Department of Neurology, Memorial Sloan-Kettering Cancer Center, New York, New York, USA

\section{Correspondence to}

Dr Jamie R Mitchell, Department of Ophthalmology, Weill Cornell Medical Center, 1305 York Ave. 11th floor, New York, NY 10021, USA;

jam9181@med.cornell.edu

Published Online First 22 May 2014

\section{CASE REPORT}

A 68-year-old man with metastatic prostate cancer was admitted with a 1-week history of bilateral 'conjunctivitis', headaches and horizontal diplopia. On examination, the superficial temporal arteries were bilaterally prominent and indurated, with conjunctival injection and chemosis. There were bilateral abduction deficits, but visual acuity and fundi were normal.

MR scan of the brain and orbits showed bilateral enhancement of the temporal arteries with intraconal fat stranding but with no extra-ocular muscle enlargement

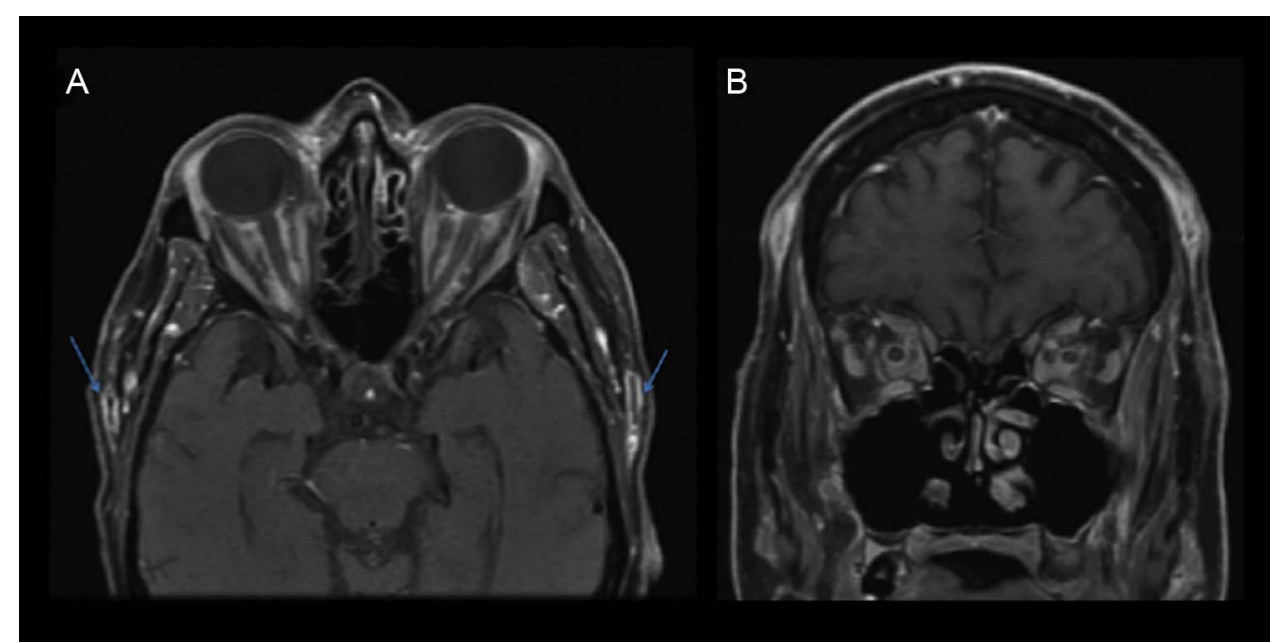

Figure 1 Contrast enhanced MRI orbits. (A) Bilateral enhancement of superficial temporal artery (arrows). (B) Intraconal fat stranding and inflammatory debris.

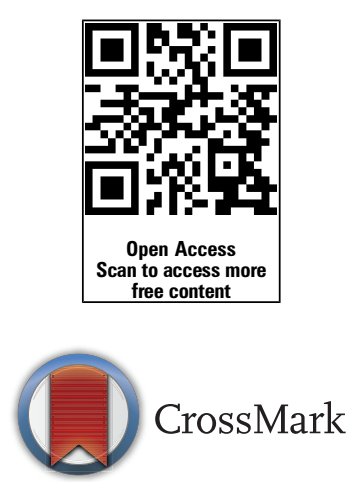

To cite: Mitchell JR, KrashinBichler I, Rosenblum M, et al. Pract Neurol 2014;14: 446-447.

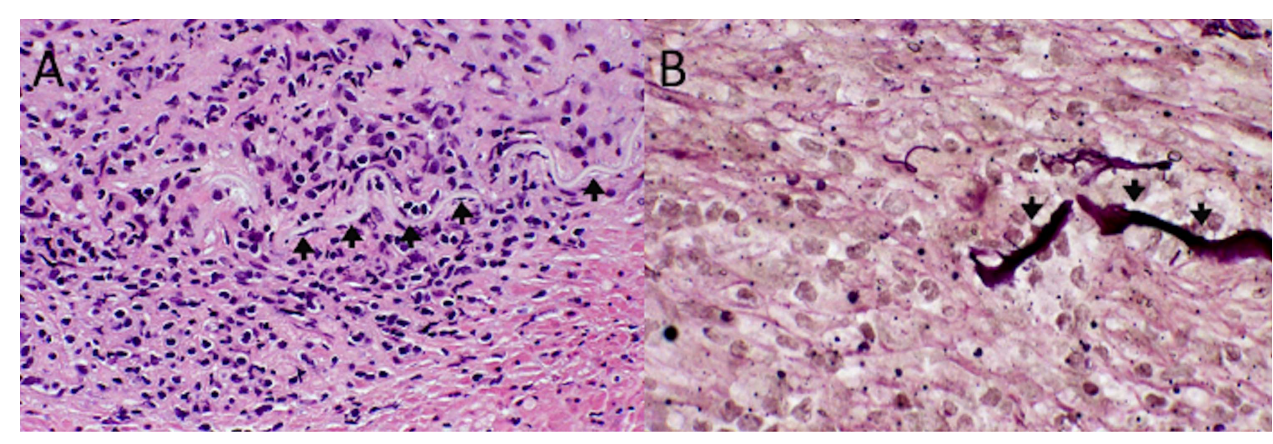

Figure 2 Pathology. (A) Chronic inflammatory infiltrate of vessel and muscle wall, internal elastic lamina (arrows) and intima. Discontinuity of the elastic lamina (left). (B) The inflammatory infiltrate has destroyed the internal elastic lamina (arrows). Superficial temporal artery (A) H\&E, $\times 40$. (B) Elastic van Gieson, $\times 100$. 


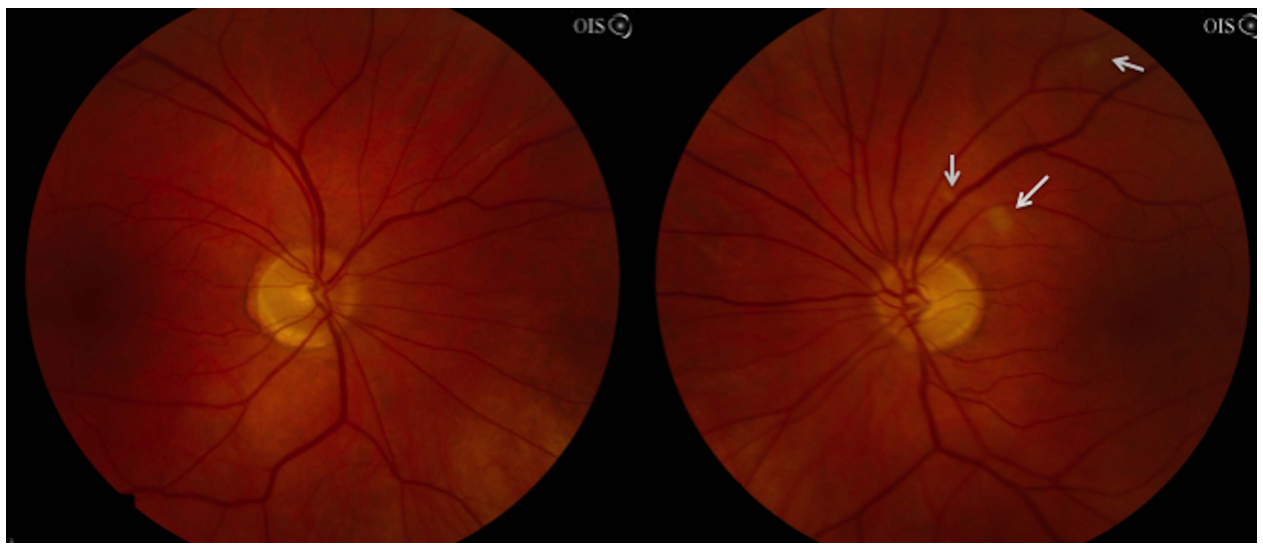

Figure 3 Fundus photographs, Note the three yellow/white lesions 'cotton wool spots' representing retinal ischaemia.

or orbital mass (figure 1A,B). His erythrocyte sedimentation rate was elevated at $103 \mathrm{~mm} / 1 \mathrm{st} \mathrm{h}(<20)$, serum C reactive protein was $14 \mathrm{mg} / \mathrm{L}(<10)$ and CSF: glucose 57 , protein 31 , cell count $<1$ analysis was normal. We gave him prednisolone $100 \mathrm{mg}$ daily, with significant improvement. A temporal artery biopsy, taken 4 days after starting prednisolone, showed 'skip' lesions of the temporal artery wall with chronic inflammatory infiltration of the intima, media and adventitia, damage to the muscle wall, fraying and destruction of the internal elastic lamina, and fibrointimal proliferation (figure $2 \mathrm{~A}, \mathrm{~B}$ ). The inflammatory infiltrate comprised small lymphocytes and histiocytes, but there were no giant cells.

Re-examination 2 weeks later showed complete resolution of orbital inflammation in both eyes. Visual acuity and visual fields remained normal, but dilated fundoscopy showed three new areas of retinal ischaemia 'cotton wool spots' within the superior arcade of the left eye (figure 3). Fluorescein angiogram showed a large vertical area of delayed choroidal perfusion.

\section{COMMENT}

Giant cell arteritis is a systemic, inflammatory vasculitis that affects small- to medium-sized arteries. Orbital inflammation is a very unusual clinical presentation of this condition. Our review of the literature found only four previous cases of giant cell arteritis presenting with bilateral orbital inflammation. ${ }^{12}$ Our case also showed MR scan findings of dramatic enhancement of the bilateral superficial temporal arteries.
Because early recognition and treatment of giant cell arteritis may prevent severe and irreversible visual loss, clinicians must consider it in elderly patients presenting with idiopathic orbital inflammation, with or without visual loss.

Acknowledgements Richard Phillips and Alan Carver were involved in the clinical patient care and provided feedback on the manuscript.

Contributors JRM was the corresponding author and contributed to the manuscript content, editing and submission. IKB and ELD contributed to the manuscript content and editing. MR contributed the pathology images and descriptions. MJD contributed to editing and content of the manuscript.

Competing interests None.

Patient consent Obtained.

Provenance and peer review Not commissioned; externally peer reviewed. This paper was reviewed by Ashwin Pinto, Southampton, UK.

Open Access This is an Open Access article distributed in accordance with the Creative Commons Attribution Non Commercial (CC BY-NC 3.0) license, which permits others to distribute, remix, adapt, build upon this work noncommercially, and license their derivative works on different terms, provided the original work is properly cited and the use is non-commercial. See: http://creativecommons.org/licenses/by$\mathrm{nc} / 3.0 /$

\section{REFERENCES}

1 Lee AG, Tang RA, Feldon SE, et al. Orbital presentation of giant cell arteritis. Graefes Arch Clin Exp Ophthalmol 2001;239:509-13.

2 Morgenstern KE, Ellis BD, Schochet SS, et al. Bilateral optic nerve sheath enhancement from giant cell arteritis. J Rheumatol 2003;30:625-7. 